Check for updates

Cite this: RSC Adv., 2019, 9, 8350

\title{
Flexible cupric oxide photocathode with enhanced stability for renewable hydrogen energy production from solar water splitting $\dagger$
}

\begin{abstract}
Yang Li iD *abc and Kai Luo ${ }^{a}$
$\mathrm{CuO}$ is a promising but unstable photocathode in solar water splitting. Herein, a flexible $\mathrm{CuO}$ photocathode is prepared and its degradation mechanisms and stabilization strategies have been discussed. Briefly, we find alkali environment and low light intensity are the critical factors in the stabilization of the $\mathrm{CuO}$ photocathode. For practical usage, a composite semiconductor layer, composed of $\mathrm{TiO}_{2}, \mathrm{La}_{2} \mathrm{O}_{3}$ and $\mathrm{NiO}$, is deposited on the $\mathrm{CuO}$ photocathode, which is proved to be effective for enhancing the stabilization of the $\mathrm{CuO}$ photocathode. $100 \%$ of the photocurrent density has been retained after 20 minutes of continuous illumination. The optimized stable photocurrent density is measured as $0.3 \mathrm{~mA}$ $\mathrm{cm}^{-2}$ at $0.5 \mathrm{~V}_{\mathrm{RHE}}$.
\end{abstract}

Received 1st February 2019 Accepted 4th March 2019

DOI: $10.1039 / c 9 r a 00865 a$

rsc.li/rsc-advances light intensity on $\mathrm{CuO}$ photocathode stability, at last we designed a multiple overlayer, which takes into consideration of advantages of each individual layer. The optimized $\mathrm{CuO}$ shows remarkably enhanced photo-stability with $100 \%$ retention of the photocurrent density after $20 \mathrm{~min}$.

From the SEM images in Fig. 1a, we can see the pre-clean $\mathrm{Cu}$ foil exposed a comparatively smooth morphology. After a fast fire treatment, a dense and brunette oxide layer grew on the metal surface. The oxide layer thickness increases as the fire treatment period extends. The average film thickness is $150 \mathrm{~nm}$ after $10 \mathrm{~s}$ of the fire treatment confirmed by the cross section SEM images, which is much thinner in comparison with the
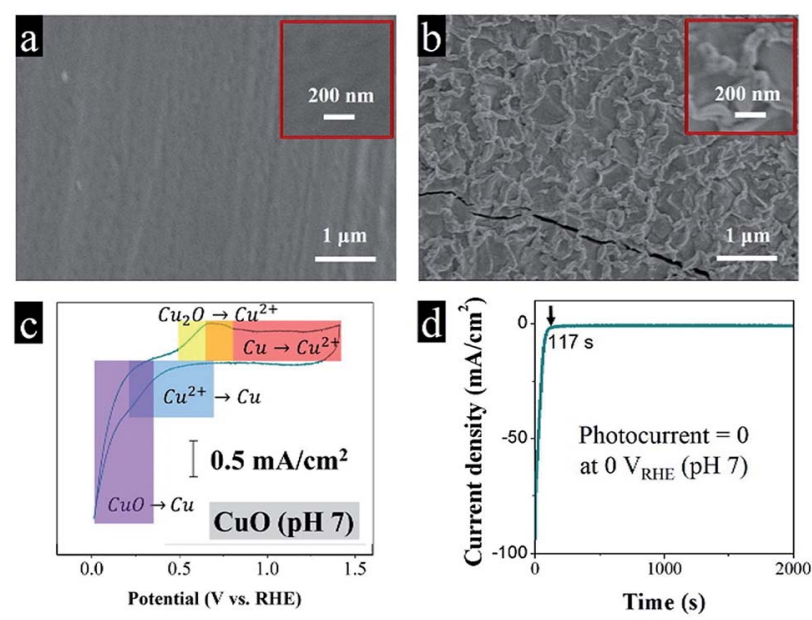

Fig. 1 SEM images of (a) the $\mathrm{Cu}$ foil and (b) the $\mathrm{CuO}$ photocathode, respectively; (c) cyclic voltammetry of the $\mathrm{CuO}$ photocathode in $1 \mathrm{M}$ $\mathrm{NaSO}_{4}$ electrolyte ( $\mathrm{pH}$ 7); (d) dark current density of the CuO photocathode at $0 \mathrm{~V}_{\mathrm{RHE}}$ in $\mathrm{pH} 7$ without any photoresponse. 
traditional calcination in a muffle furnace. ${ }^{7}$ The moderate thickness is convenient for the separation of charge carriers, preventing fast recombination. ${ }^{8}$ The metal interlayer serves to transfer electrons, while the oxide layer is responsible for absorbing photons and generating free electrons. Fig. 1b implies the fast fire treatment caused thermal expansion and contraction, produced a rough and wrinkled oxide layer.

It is a common that acidic electrolytes benefit hydrogen evolution reaction, because of high concentrations of protons. ${ }^{9}$ In previous studies, most of the colleagues try their best to improve the performance of $\mathrm{CuO}$ photocathode in $\mathrm{Na}_{2} \mathrm{SO}_{4}$ electrolyte. ${ }^{10,11}$ However, the cyclic voltammetry in Fig. 1c demonstrates that $\mathrm{Cu}^{(2+)} \mathrm{O}$ spontaneously corrupts to $\mathrm{Cu}^{(0)}$ below $0.3 \mathrm{~V}_{\mathrm{RHE}}$ (eqn (1)), which is buttressed by our photoelectrochemical test in Fig. 1d, predictably, the CuO photocathode deactivated abruptly in dark (the dark current density reached $93 \mathrm{~mA} \mathrm{~cm}^{-2}$ at $0 \mathrm{~V}_{\mathrm{RHE}}$ ), and totally no photocurrent can be observed under illumination (the dark current density decayed to a stable value of $0.5 \mathrm{~mA} \mathrm{~cm}^{-2}$ ). After the reaction, the brunette absorbing layer disappeared, recovered a shiny metallic luster.

$$
\mathrm{CuO}+2 \mathrm{e}^{-}+2 \mathrm{H}^{+} \rightarrow \mathrm{Cu}+\mathrm{H}_{2} \mathrm{O}, E^{\theta}=+0.3 \mathrm{~V}_{\mathrm{RHE}}
$$

To avoid the fast self-corrosion of the $\mathrm{CuO}$ photocathode below $0.3 \mathrm{~V}_{\mathrm{RHE}}$, at the same time for the further combination with the photoanodes, we increased the voltage applied to $\mathrm{CuO}$ photocathode to $0.5 \mathrm{~V}_{\mathrm{RHE}}$, and at this time we found a photocurrent spike of $0.8 \mathrm{~mA} \mathrm{~cm} \mathrm{~cm}^{-2}$ appeared, followed by a continuous decrease to $0.1 \mathrm{~mA} \mathrm{~cm}^{-2}$ after $1000 \mathrm{~s}$ irradiation in Fig. 2a. The result implies that a slow deactivation process still exists, similar to the phenomenon in Jang's work. ${ }^{3}$ In the retardatory deactivation process, the surface $\mathrm{Cu}^{(2+)} \mathrm{O}$ is reduced to $\mathrm{Cu}^{(0)}$, eqn (1), by the energetic photo-induced electrons. The accumulated $\mathrm{Cu}$ layer isolates the inner $\mathrm{CuO}$ from the electrolyte, which slows down the current decay. The extreme instability of $\mathrm{CuO}$ photocathode forced us to find a new path of using it.

After realizing that $\mathrm{CuO}$ is extremely sensitive to protons, which causes fast photo-induced inactivation, we tried to raise the $\mathrm{pH}$ value and reduce the proton concentration. Adjusting $\mathrm{pH}$ value is often an effective means for changing the course of a chemical reaction. ${ }^{12,13}$ After substituting $\mathrm{NaOH}$ for $\mathrm{Na}_{2} \mathrm{SO}_{4}$ in the electrolyte, we discovered that the $\mathrm{CuO}$ photocathode produced a photocurrent density of $1.2 \mathrm{~mA} \mathrm{~cm} \mathrm{~cm}^{-2}$ at $0.5 \mathrm{~V}_{\mathrm{RHE}}$ in pH 13 without any decay during $1000 \mathrm{~s}$. It is meaningful to find adjusting $\mathrm{pH}$ value has an ability to alter the selectivity of the CuO photocathode, which seems the easiest way to stabilize the $\mathrm{CuO}$ photocathode. As shown in Fig. 2b, according to the previous studies, the Fermi level of $\mathrm{CuO}$ is near to $0.8 \mathrm{~V}_{\mathrm{RHE}}$, while the calculated band gap is $1.6 \mathrm{eV} .^{3,14} \mathrm{As} \mathrm{CuO}$ is a p-type semiconductor, assuming that the energy gap between Fermi level and valence band is $0.3 \mathrm{eV},{ }^{15,16}$ the conduction band and valence band are $-0.5 \mathrm{~V}_{\mathrm{RHE}}$ and $1.1 \mathrm{~V}_{\mathrm{RHE}}$, respectively. Consequently, in the neutral condition, photo-excited electrons in the conduction band move downward and reduce surface $\mathrm{CuO}$ to $\mathrm{Cu}$. As a result, we observed a fast descent of the photocurrent density. As mentioned above, the accumulated $\mathrm{Cu}$ layer isolates
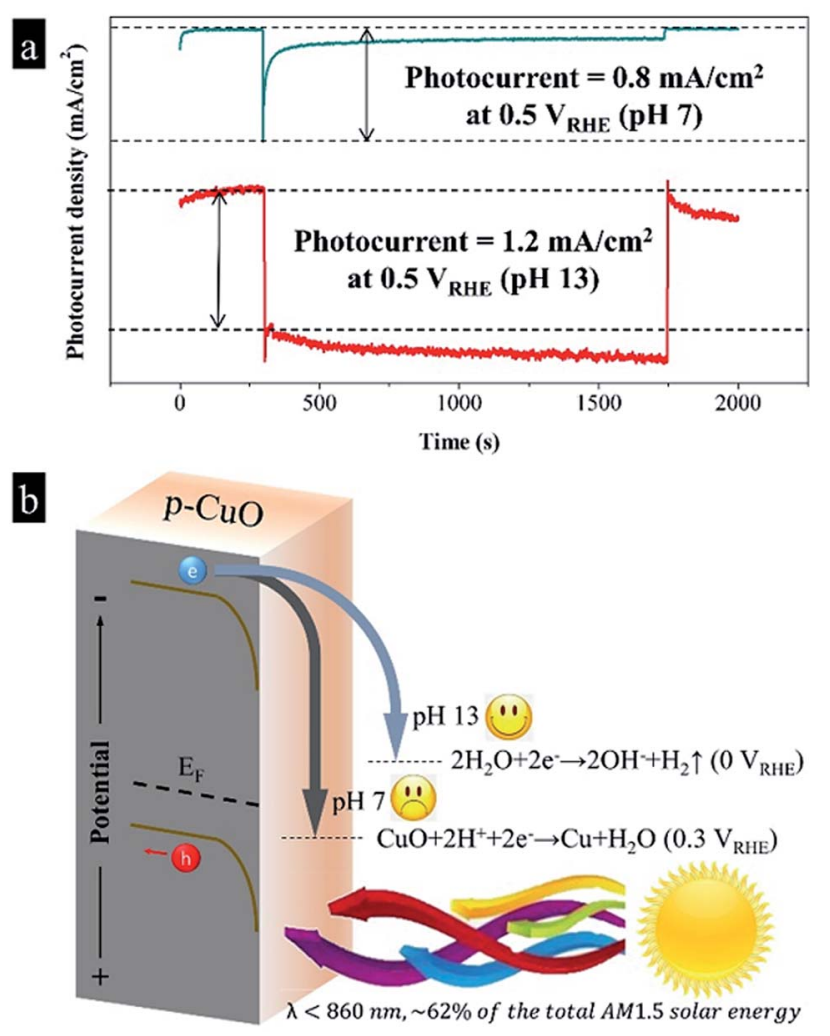

Fig. 2 (a) The photoelectrochemical stabilities of the $\mathrm{CuO}$ photocathodes in $1 \mathrm{M} \mathrm{Na}_{2} \mathrm{SO}_{4}(\mathrm{pH} 7)$ and $1 \mathrm{M} \mathrm{NaOH}(\mathrm{pH} 13)$ electrolytes at 0.5 $V_{\text {RHE }}$, respectively; (b) schematic plot of the band structure and photodeactivation mechanism of the $\mathrm{CuO}$ photocathode.

the inner $\mathrm{CuO}$ from the electrolyte, which slows down the current decay. Comparatively, photo-induced electrons selectively reduce water into hydrogen in the basic environment, while the deactivation reaction is somewhat neglected. The least of perfection, in the basic solution the good stability was accompanied by a slow recovery of the dark current. ${ }^{4}$

$$
\mathrm{CuO}+\mathrm{H}_{2} \mathrm{O}+2 \mathrm{e}^{-} \rightarrow \mathrm{Cu}+2 \mathrm{OH}^{-}, E^{\theta}=+0.3 \mathrm{~V}_{\mathrm{RHE}}
$$

After tuning the light intensity from $100 \mathrm{~mW} \mathrm{~cm}^{-2}$ to $20 \mathrm{~mW}$ $\mathrm{cm}^{-2}$, it is really interesting to find the relaxation of dark current disappeared, although the photocurrent density decreased to $0.3 \mathrm{~mA} \mathrm{~cm}{ }^{-2}$. It is not difficult to associate this relationship with the shift of Fermi level. We interpret the mechanism in Fig. 3, under the powerful beam, the Fermi level transfers to the potential that is higher than the $E^{\theta}(\mathrm{Cu} / \mathrm{CuO})$, in this case, the photo-excited electrons partially reduce surface $\mathrm{CuO}$ to $\mathrm{Cu}$ (eqn (2)), followed by generating $\mathrm{Cu}(\mathrm{OH})_{2}$ spontaneously (eqn (3)). $\mathrm{Cu}(\mathrm{OH})_{2}$ is a weak p-type semiconductor, leading to the relaxation phenomenon. Oppositely, the Fermi level stays below the $E^{\theta}(\mathrm{Cu} / \mathrm{CuO})$ under low light intensity, which inspires the photo-electrons to fulfill the water reduction. Consequently, CuO photocathode shows a satisfactory photostability at $0.5 \mathrm{~V}_{\mathrm{RHE}}$ with $100 \%$ retention of the photocurrent density after $20 \mathrm{~min}$.

$$
\mathrm{Cu}+2 \mathrm{OH}^{-}+2 \mathrm{~h}^{+} \rightarrow \mathrm{Cu}(\mathrm{OH})_{2}, E^{\theta}=-0.2 \mathrm{~V}_{\mathrm{RHE}}
$$



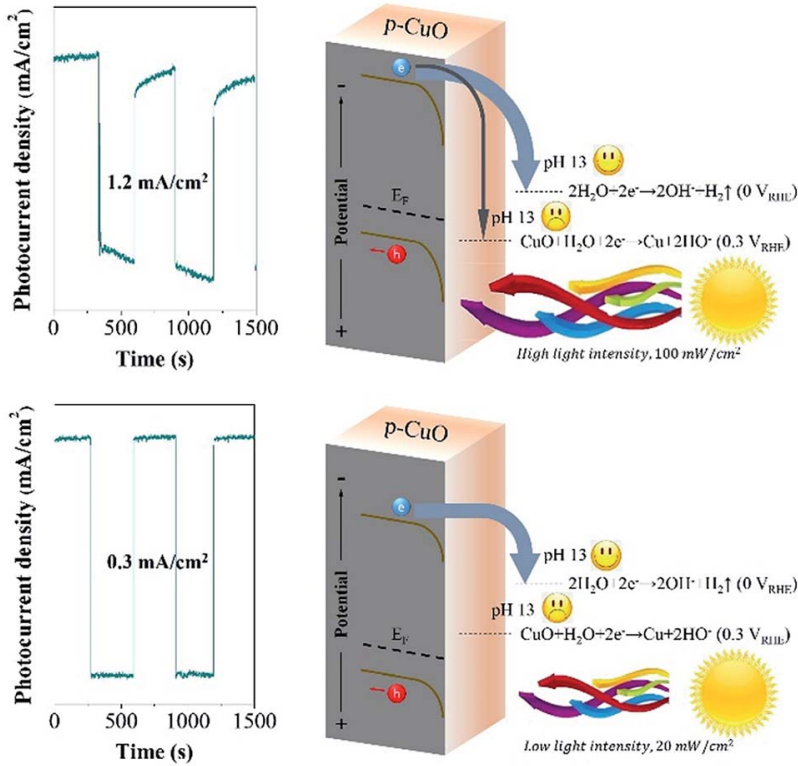

Fig. 3 The comparison of the mechanism at $\mathrm{pH} 13$ under high light intensity $\left(100 \mathrm{~mW} \mathrm{~cm}^{-2}\right)$ and low light intensity $\left(20 \mathrm{~mW} \mathrm{~cm}^{-2}\right)$.

As known to all, the power of sunlight varies with time in real life, it is really difficult to limit the maximum value from 100

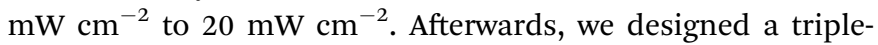
component protective layer of $\mathrm{TiO}_{2} / \mathrm{La}_{2} \mathrm{O}_{3} / \mathrm{NiO}$ to neutralize the disadvantage, the thicknesses of $\mathrm{TiO}_{2}, \mathrm{La}_{2} \mathrm{O}_{3}$ and NiO were $50 \mathrm{~nm}, 100 \mathrm{~nm}$ and $18 \mathrm{~nm}$, respectively. The different film thicknesses were obtained by controlling the dip-coating processes (ESI $\dagger$ ). The multilayer structure not only controls the light intensity within an appropriate range but also has a catalytic influence. The $\mathrm{TiO}_{2}$ wrapped the $\mathrm{CuO}$ surface and reduced the surface roughness in Fig. 4a, while the subsequent $\mathrm{La}_{2} \mathrm{O}_{3} / \mathrm{NiO}$ totally covered the substrate, making the surface smooth under the electron microscope (Fig. 4b). The optimized
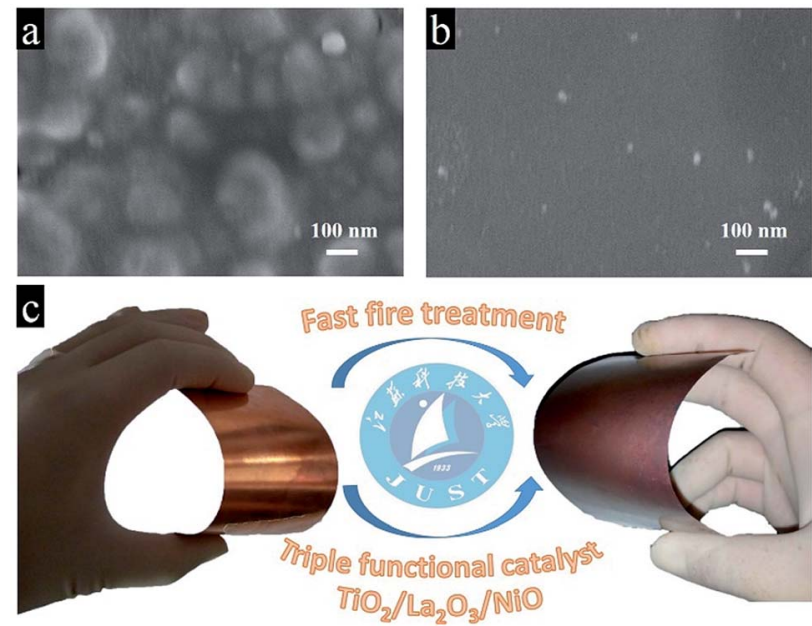

Fig. 4 The surface SEM images of (a) the $\mathrm{CuO} / \mathrm{TiO}_{2}$ and (b) the $\mathrm{CuO} /$ $\mathrm{TiO}_{2} / \mathrm{La}_{2} \mathrm{O}_{3} / \mathrm{NiO}$; (c) schematic plot of the preparation of the $\mathrm{CuO} /$ $\mathrm{TiO}_{2} / \mathrm{La}_{2} \mathrm{O}_{3} / \mathrm{NiO}$ photocathode.
CuO photocathode (Fig. 4c) produced a thoroughly stable photocurrent density of $0.3 \mathrm{~mA} \mathrm{~cm}^{-2}$ at $0.5 \mathrm{~V}_{\mathrm{RHE}}$ under AM $1.5 \mathrm{G}$ condition for $20 \mathrm{~min}$, meanwhile, the dark current density recovers quickly and keeps steady, shown in Fig. 5a.

The high stability of around $100 \%$ is found to be the highest reported value in terms of a plain $\mathrm{CuO}$ photocathode (Table 1). To certify the fundamental chemical stability, X-ray photoelectron spectroscopy (XPS) was applied to detect the surface properties and oxidation states, shown in Fig. 5b. X-ray induced Auger electron spectroscopy (XAES) was employed in the $\mathrm{Cu}$ LMM region to get information of the oxidation state of $\mathrm{Cu}$ (Fig. 5b), as the $\mathrm{Cu} 2 \mathrm{p}$ binding energies are almost indistinguishable. The Cu LMM peak at $917.7 \mathrm{eV}$ was assigned to $\mathrm{Cu}^{2+}$. The binding energies of $\mathrm{Ti} 2 \mathrm{p}_{3 / 2}$, La $3 \mathrm{~d}_{5 / 2}$ and $\mathrm{Ni} 2 \mathrm{p}_{3 / 2}$ were 458.7, 834.5 and $835.7 \mathrm{eV}$, respectively, corresponding to $\mathrm{Ti}^{(4+)}$, $\mathrm{La}^{(3+)}$ and $\mathrm{Ni}^{(2+)}$. Furthermore, the XPS spectra before and after reactions in Fig. $\mathrm{S} 1 \dagger$ indicate the metal oxidation states in $\mathrm{Cu}^{(2+)} \mathrm{O}, \mathrm{Ti}^{(4+)} \mathrm{O}_{2}, \mathrm{La}^{(3+)}{ }_{2} \mathrm{O}_{3}$ and $\mathrm{Ni}^{(2+)} \mathrm{O}$ did not change after $30 \mathrm{~min}$ reaction, which met our expectations. Moreover, the construction of this multi-layer photocathode is depicted in Fig. 5c. Many researchers predicted that the conduction band position of $\mathrm{CuO}$ is not negative enough to drive the hydrogen evolution reaction. In fact, we found $\mathrm{CuO}$ possesses a conduction band edge near to $-0.5 \mathrm{~V}_{\mathrm{RHE}}$, which means the photoelectrocatalytic hydrogen evolution from water by $\mathrm{CuO}$ should be thermodynamically favorable. In the present work, the photo-induced electrons in $\mathrm{p}-\mathrm{CuO}$ were driven by the depletion layer ( $\mathrm{p}-\mathrm{CuO} / \mathrm{n}-\mathrm{TiO}_{2} \mathrm{p}-\mathrm{n}$ junction) to $\mathrm{n}-\mathrm{TiO}_{2}$, then penetrated the $\mathrm{La}_{2} \mathrm{O}_{3}$ layer. Herein, $\mathrm{La}_{2} \mathrm{O}_{3}$ can be considered as a proton insulating layer. ${ }^{17}$ After hundreds of attempts, we found that $\mathrm{La}_{2} \mathrm{O}_{3}$ is one of the materials that effective for the stabilization
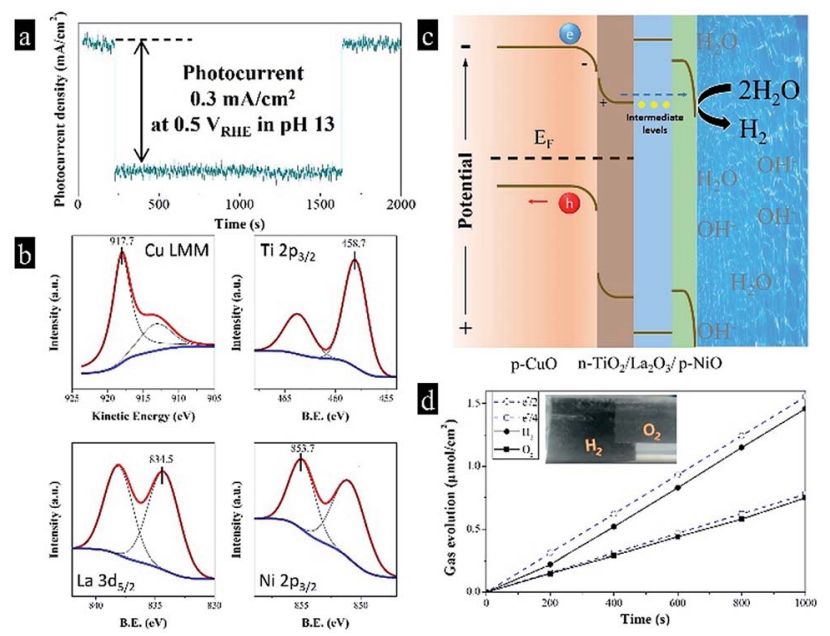

Fig. 5 (a) Photoelectrochemical response and stability of the $\mathrm{TiO}_{2} /$ $\mathrm{La}_{2} \mathrm{O}_{3} / \mathrm{NiO}$ coated $\mathrm{CuO}$ photocathode; (b) Cu LMM, Ti 2p, La 3d and Ni $2 \mathrm{p} \mathrm{X}$-ray photoelectron spectra (XPS) of the $\mathrm{TiO}_{2} / \mathrm{La}_{2} \mathrm{O}_{3} / \mathrm{NiO}$ coated $\mathrm{CuO}$ photocathode; (c) schematic plot of the band structure and water reduction mechanism of the $\mathrm{TiO}_{2} / \mathrm{La}_{2} \mathrm{O}_{3} / \mathrm{NiO}$ coated $\mathrm{CuO}$ photocathode; (d) gas evolution from the $\mathrm{CuO} / \mathrm{TiO}_{2} / \mathrm{La}_{2} \mathrm{O}_{3} / \mathrm{NiO}$ photocathode and the $\mathrm{Pt}$ counter electrode, which is compared with the evolution of $\mathrm{H}_{2}\left(\mathrm{e}^{-} / 2\right)$ and $\mathrm{O}_{2}\left(\mathrm{e}^{-} / 4\right)$ expected from the photocurrent. The measurement was performed at constant potential $0.5 \mathrm{~V} v$ s. RHE. 
Table 1 The stabilities of the CuO photocathodes for PEC water splitting in the literature

\begin{tabular}{|c|c|c|c|c|c|}
\hline Electrolyte & $\begin{array}{l}\text { Light intensity } \\
\left(\mathrm{mW} \mathrm{cm}^{-2}\right)\end{array}$ & Bias $\left(\mathrm{V}_{\mathrm{RHE}}\right)$ & Constructure & Stability & Ref. \\
\hline $0.25 \mathrm{M} \mathrm{Na}_{2} \mathrm{SO}_{4}$ & 109 & 0 & $\mathrm{ZnO} / \mathrm{CuO}$ & $40 \%$ (3 min) & 21 \\
\hline $0.5 \mathrm{M} \mathrm{Na}_{2} \mathrm{SO}_{4}$ & 100 & 0.2 & $\mathrm{CuO}$ & $80 \%(15 \mathrm{~min})$ & 3 \\
\hline $0.25 \mathrm{M} \mathrm{Na}_{2} \mathrm{SO}_{4}$ & 100 & 0.2 & $\mathrm{ZnO} / \mathrm{CuO}$ & $90 \%(6 \mathrm{~min})$ & 23 \\
\hline $0.5 \mathrm{M} \mathrm{Na}_{2} \mathrm{SO}_{4}$ & 100 & 0 & $\mathrm{Au}-\mathrm{Pd} / \mathrm{CuO}$ & $90 \%(20 \mathrm{~min})$ & 24 \\
\hline $1 \mathrm{M} \mathrm{NaOH}$ & 100 & 0.5 & $\mathrm{CuO}$ & $\sim 100 \%(20 \mathrm{~min})$ & Present work \\
\hline
\end{tabular}

of copper oxide, and the stability enhanced with the increasing thickness, until a thickness of $100 \mathrm{~nm}$ can balance the stability and the activity. Although $\mathrm{La}_{2} \mathrm{O}_{3}$ has a large theoretical band gap (3.8-5.8 eV), it contains deep levels and trap-states, which reduce the band gap ( $2.9 \mathrm{eV}$, fluorescence emission at $416 \mathrm{~nm})$ and the resistivity $(\sim 10 \mathrm{k} \Omega \mathrm{cm}) .{ }^{18-20}$ The deep levels and trapstates form intermediate levels in the large band gap, facilitating the charge transportation. Thus, $\mathrm{La}_{2} \mathrm{O}_{3}$ accepts the photoinduced electrons from $\mathrm{TiO}_{2}$ and allow them to pass through. Finally, the electrons enter a second depletion layer, as p-NiO equilibrates with the electrolyte, and complete the water reduction. By the way, we have to mention that $\mathrm{TiO}_{2}, \mathrm{La}_{2} \mathrm{O}_{3}$ and $\mathrm{NiO}$ perform their respective duties and are indispensable. The amounts of $\mathrm{H}_{2}$ and $\mathrm{O}_{2}$ that evolved were determined by gas chromatography. In Fig. 5d, the theoretical amounts of gases expected from photocurrent generations are compared with the actual generation of the gases. The difference between these two values is represented by the faradaic efficiency. The faradaic efficiency of the hydrogen evolution was determined to be $94 \%$ when the system was stabilized and showed a steady state. The rest $6 \%$ could be accounted for the inefficient gas collection (gas dissolution and strong adsorption on the electrode surface) and some parasitic electrochemical processes.

\section{Conclusions}

Cupric oxide is not chemically inert in aqueous solution under illumination because of its sensitivity to protons, which makes a painstaking process of fabricating stable $\mathrm{CuO}$ photocathodes. It is found the photo-stability of CuO photocathode is highly dependent on the $\mathrm{pH}$ value, working potential, light intensity and protective overlayer. After optimization, we applied $\mathrm{CuO}$ photocathode in basic environment coupled with a multifunctional semiconductor overlayer, i.e. $\mathrm{TiO}_{2} / \mathrm{La}_{2} \mathrm{O}_{3} / \mathrm{NiO}$, in which p$\mathrm{CuO} / \mathrm{n}-\mathrm{TiO}_{2}$ forms a $\mathrm{p}-\mathrm{n}$ junction, accelerating the charge separation, while $\mathrm{La}_{2} \mathrm{O}_{3}$ and $\mathrm{NiO}$ act as a proton-isolating layer and a catalyst layer, respectively. The photocurrent density is 0.3 $\mathrm{mA} \mathrm{cm}{ }^{-2}$ at $0.5 \mathrm{~V}_{\mathrm{RHE}}$ with $100 \%$ retention after $20 \mathrm{~min}$, as well as the dark current density.

\section{Conflicts of interest}

There are no conflicts to declare.

\section{Acknowledgements}

This work has been supported by National Nature Science Foundation of China (No. 21606171), China Postdoctoral Science Foundation (No. 2015M580205 and 2017T100160), and Tianjin University Independent Innovation Foundation (1705).

\section{Notes and references}

1 M. G. Walter, E. L. Warren, J. R. McKone, S. W. Boettcher, Q. Mi, E. A. Santori and N. S. Lewis, Chem. Rev., 2010, 110, 6446-6473.

2 K. Sivula, Chimia, 2013, 67, 155-161.

3 Y. J. Jang, J. W. Jang, S. H. Choi, J. Y. Kim, J. H. Kim, D. H. Youn, W. Y. Kim, S. Han and J. Sung Lee, Nanoscale, 2015, 7, 7624-7631.

4 X. B. Chen, S. H. Shen, L. J. Guo and S. S. Mao, Chem. Rev., 2010, 110, 6503-6570.

5 Y. Li and H. Chen, J. Mater. Chem. A, 2016, 4, 14974-14977.

6 Y. Li, N. Guijarro, X. Zhang, M. S. Prevot, X. A. Jeanbourquin, K. Sivula and H. Chen, ACS Appl. Mater. Interfaces, 2015, 7, 16999-17007.

7 Y. Li, X. Zhang, H. Chen and Y. Li, Catal. Commun., 2015, 66, 1-5.

8 Y. Li, Z. Yu, J. Meng and Y. Li, Int. J. Hydrogen Energy, 2013, 38, 3898-3904.

9 S. Trasatti, J. Electroanal. Chem. Interfacial Electrochem., 1972, 39, 163-184.

10 Y. F. Lim, C. S. Chua, C. J. Lee and D. Chi, Phys. Chem. Chem. Phys., 2014, 16, 25928-25934.

11 Z. Yu, J. Meng, Y. Li and Y. Li, Int. J. Hydrogen Energy, 2013, 38, 16649-16655.

12 S. Štrbac and R. R. Adžić, Electrochim. Acta, 1996, 41, 29032908.

13 S. Yasutomi, T. Morita and S. Kimura, J. Am. Chem. Soc., 2005, 127, 14564-14565.

14 Q. Huang, F. Kang, H. Liu, Q. Li and X. Xiao, J. Mater. Chem. A, 2013, 1, 2418-2425.

15 Y. Matsumoto, J. Solid State Chem., 1996, 126, 227-234.

16 Y. Li, X. Zhang, S. Jiang and Y. Li, J. Catal., 2014, 320, 208214.

17 D. Bae, B. Seger, P. C. K. Vesborg, O. Hansen and I. Chorkendorff, Chem. Soc. Rev., 2017, 46, 1933-1954. 
18 G. Shang, P. W. Peacock and J. Robertson, Appl. Phys. Lett., 2004, 84, 106-108.

19 C. G. Hu, H. Liu, W. T. Dong, Y. Y. Zhang, G. Bao, C. S. Lao and Z. L. Wang, Adv. Mater., 2007, 19, 470-474.

20 S. S. Kale, K. R. Jadhav, P. S. Patil, T. P. Gujar and C. D. Lokhande, Mater. Lett., 2005, 59, 3007-3009.

21 A. Kargar, Y. Jing, S. J. Kim, C. T. Riley, X. Pan and D. Wang, ACS Nano, 2013, 7, 11112-11120.
22 M. Patel, R. Pati, P. Marathey, J. Kim, I. Mukhopadhyay and A. Ray, J. Electrochem. Soc., 2016, 163, H1195-H1203.

23 F. Wu, F. Cao, Q. Liu, H. Lu and L. Li, Sci. China Mater., 2016, 59, 825-832.

24 S. Masudy-Panah, R. Siavash Moakhar, C. S. Chua, A. Kushwaha and G. K. Dalapati, ACS Appl. Mater. Interfaces, 2017, 9, 27596-27606.

25 J. Han, X. Zong, X. Zhou and C. Li, RSC Adv., 2015, 5, 1079010794. 